\title{
La construcción de la identidades femeninas en la representación artística de las mujeres en la Historia de Madrid
}

\author{
The construction of female identities in the artistic \\ representation of women in the History of Madrid
}

PALOMA Rodera Martínez

Universidad Antonio de Nebrija

Recibido: $12-11-2020$

Aceptado: 10-2-2021

doi: https://doi.org/10.20318/femeris.2021.6401

\begin{abstract}
Resumen. Este artículo utiliza el arte como una fuente de análisis social. El estudio de caso realizado es el de la construcción de las diferentes identidades femeninas en la representación artística en la Historia de Madrid. Se ha realizado un análisis de diferentes mujeres: María Guerrero, Manuela Malasaña, Isabel II, Santa María de la Cabeza, Catalina de Aragón, María de Zayas y Sotomayor, María Isidra de Guzmán y de la Cerda, Clara Campoamor, Juanita Cruz y Cibeles. Para su posterior análisis se han escogido representaciones plásticas representativas de cada una de ellas. Las técnicas seleccionadas son dibujo, pintura y escultura. El género escogido es el del retrato. La metodología utilizada para el análisis de las imágenes proviene de la Historia del Arte. Se ha empleado una metodología iconográfico-iconológica en la que se aplican los tres niveles: de descripción pre-iconográfica, el nivel de análisis iconográfico y el nivel de análisis iconológico. En una segunda fase del estudio de caso, se presenta la intervención del arte en lo social a través de sus imágenes, que pasan a convertirse en iconos. En el artículo se presentan las conclusiones de la investigación que demuestran cómo esos iconos se relacionan entre sí generando identidad colectiva, no solo como parte de las biografías individuales de las mujeres seleccionados.
\end{abstract}

Palabras clave: arte, análisis social, identidades femeninas, historia, urbano.

Abstract. This paper use the art as a source of social analysis. The case study made consists in a construction of the different feminines identities in the artistic representation in Madrid history. It has been done an analysis from different women: María Guerrero, Manuela Malasaña; Isabel II, Santa María de la Cabeza, Catalina de Aragón, Maria de Zayas y Sotomayor, María Isidra de Guzmán y de la Cerda, Clara Campoamor, Juanita Cruz and Cibeles. Representative plastic representations of each of them have been chosen for further analysis. The selected techniques are drawing, painting and sculpture. The artistic genre chosen is the portrait. The methodology used for the analysis of the images comes from the History of Art using an iconographic-iconological methodology in which the three levels are applied: pre-iconographic description, the level of iconographic analysis and the level of iconological analysis. In a second phase of the case study, the intervention of art in the social is presented through its images, which become icons. This paper presents the conclusions of the research that shows how these icons are related to each other, generating a collective identity, not only as part of the individual biographies of the selected women..

Keywords: art, social analysis, female identity, history, urban.

"prodera@nebrija.es 


\section{Introducción}

En este artículo se trabaja sobre la temática de construcción identitaria a través de un análisis artístico, y, en concreto, de género, ya que estudia figuras femeninas. Además, no es solo un análisis individual, sino social. Todo ello hecho desde la reconstrucción a través de lo artístico, utilizando la obra plástica como elemento de creación de parámetros. Hay un valor artístico y, a su vez, de intervención que abarca generaciones de la sociedad centrando la atención en su historia.

Se parte de la premisa de una pluralidad en el concepto de mujer. Como ya se describe en el título del artículo, no existe una única identidad femenina o un modo único de ser mujer. Este hecho se constatará a través de las obras seleccionadas y su análisis.

El enfoque de la comunicación es multidisciplinar, ya que utiliza las herramientas que aportan disciplinas como la Sociología, la Estética, la Historia del Arte o las Artes Plásticas para poder estudiar de forma completa el objeto de análisis de una forma más adecuada. Se trata de un espacio intersticial que sitúa al lector en la confluencia de varias experiencias.

La Sociología se utiliza dentro de las premisas del estudio con autores como Goffman y un enfoque micro o Wolf como estudioso del éste. En cuanto a la Estética se incluyen las ideas de Lukács y Susan Sontag en apreciación de obras. En el artículo se alude a la implicación de quien observa, que como el propio autor define en su Estética, se refiere a los modos de conocimiento y en los que el espectador es "portador de una totalidad de impresiones, pensamientos y conexiones reales. La adaptación del comportamiento subjetivo tiene que ser por fuerza, también, una síntesis de tales elementos" (Lukács, 1974, pág.74-75). De la parte de la Historia del Arte, el estudio se enmarca en autores como Estrella de Diego o Patricia Mayayo. Se completa el cuerpo de disciplinas con la inclusión de la teoría feminista con autoras como Marian López Fernández-Cao y su modo de entender el feminismo como una crítica de la representación. De este modo, se aplica la perspectiva de género al análisis del estudio.

Con este estudio nos proponemos crear una genealogía femenina, fuera de los parámetros establecidos por el patriarcado. Así como reivindicar el papel de la mujer en la historia, estableciendo un rol central de configuradora de identidad, no sólo individual, sino también colectiva y vigente. Utilizaremos para ello el arte como esa fuente de análisis social que nos permite conocer y conocernos. Y, por último, el estudio se propone establecer una señalización de cada una de las biografías individuales de las mujeres seleccionadas y sus representaciones.

Vamos a realizar un repaso por lo artístico en su función social como medio para poder expresar y contar la historia. Empezaremos con una descripción metodológica y de fondo, relativa a la obtención de la información para la construcción de las identidades.

Después pasaremos a ver qué es lo femenino, entendiéndolo como un concepto amplio que engloba rasgos y características. Se hará referencia a las construcciones socioculturales de género polarizadas entre masculinidad y feminidad y que han sido entendidas tradicionalmente como expresión individual de una tendencia sexual concreta. 
El siguiente vértice, que es fundamental para entender el hilo en el que se mueve este artículo, se refiere a la función del arte y a la pieza clave que puede suponer en el estudio de la sociedad; viajaremos por la relación simbiótica que han tenido ambos a lo largo de la Historia de nuestras sociedades occidentales.

Como iremos viendo, las biografías de las mujeres escogidas van ligadas a las vidas de las ciudades. En este caso, entre Madrid y nuestras diez encarnaciones de lo que es ser mujer. El arte es capaz de ser un vehículo que nos permite conocer la historia y entender esos modelos de mujer, esas formas de generar identidades de forma plural.

Es imprescindible entender la importancia del retrato, de la sensibilidad del artista, de la intención y de la intuición. Ésta es una historia con una perspectiva de género, que reivindica el papel de las mujeres en la historia y que nos ayuda a, conociendo nuestro pasado, saber mejor quienes somos para entender nuestro presente.

Es una nota distintiva en el modo en el que se ha procedido para la elaboración de estas páginas, que son la documentación del resultado de una investigación artística con apoyo de la Comunidad Autónoma de Madrid, lo que significa que hay una metodología propia del arte y la cultura. Se sitúa en una confluencia entre la transdisciplinaridad y la posibilidad de generar un conocimiento a través del estudio del arte.

A continuación, rescatamos las palabras de Wolf al respecto de la microsociología de Goffman en relación con los roles representados:

El segundo polo fundamental del discurso goffmaniano está representado, como ya he dicho, por el problema de la naturaleza de los actos sociales y de su sí mismo. [...] ¿Cómo se pueden definir y quiénes son los participantes en la interacción? ¿Qué es lo que se pone en juego en los encuentros sociales? ¿Cuál es la relación entre los roles sociales desempeñados por los actores, y los actores mismos en su papel de interactores? [...] hay que distinguir en la interacción lo que se está representando, lo que constituye la definición de la situación y del sí mismo de los participantes, de aquello que actualiza la representación y la definición del propio sí mismo. Hay una separación entre quien representa y aquello que es representado, entre el actor y el personaje, entre quien pretenda ser un cierto tipo de persona y el cierto tipo de persona que aquél pretende ser. Más allá de los múltiples roles sociales que se toman y se representan, está que los representa y los encarna. (Wolf, 1982, pág. 61)

Es necesario destacar la individualidad como rasgo propio de la sociedad capitalista en la que estamos inscritos. De forma especial por la paradoja que se produce entre esta vivencia de la individualidad y, al mismo tiempo, la necesidad de pertenencia a lo colectivo.

Por otro lado, hemos reinventado los ritos de paso y rituales pertenecientes a la religión, sustituyéndolos por otros que giran en torno al culto al cuerpo (en el ámbito físico, médico y espiritual). Los valores tradicionales respecto a la familia, la sexualidad, el colectivo o el anonimato han sido sobrepasados, por ello, las reglas han cambiado. Pero aun así necesitamos rituales, el ser humano sigue necesitando puntos y ciclos que referencien sus experiencias cotidianas. 
Entendemos el arte como reflejo y espejo de una sociedad que adquiere vigencia al conectarse directamente con el presente. Los fundamentos de la investigación giran en torno a tres elementos: el arte, la mujer y la ciudad.

\section{El arte como fuente de análisis sociológico}

El arte en los últimos años se ha virado hacia un modo de mostrarnos a la mujer de una forma empoderada ${ }^{1}$, valiente. Ya tenemos muchos de esos componentes si analizamos cuáles son los mensajes que llegan directamente de esa comunicación en las voces femeninas que aparecen en las representaciones de las mujeres que analizamos en este estudio de caso.

Este análisis conecta directamente con La selva de los símbolos de Turner o las consideraciones del ritual y lo sagrado de Mary Douglas. Entendemos el arte como un principio que surge cuando las necesidades básicas están cubiertas, como una manifestación elevada del ser humano que va a interpretar la realidad o va a crear nuevas. El arte es una plataforma, es esa herramienta que tenemos para expresarnos.

Pensemos en las instalaciones artísticas o en la intervención de los espacios públicos, el arte de contexto y la revolución de internet. Todo ello son eso, expresiones que han posibilitado modos de conocer, maneras de presentarse y que han influido directamente en nuestros modos de relacionarnos. Sirvan de ejemplo los trabajos de las artistas Marina Abramovic en el ámbito internacional, como la performance desarrollada en el MoMA de Nueva York en 2010 The artist is present. 0, en el ámbito nacional, la obra de Dora García que utiliza la web para explorar los límites entre la realidad y la ficción en piezas como Todas las historias, activo desde 2001.

Además, el arte y la cultura nos dan medios para construirnos como personas, para la formación de la personalidad individual y de la identidad de los pueblos. En este caso, el arte es capaz de generar un espíritu crítico en la persona y, de esa manera, hacernos crecer, siendo personas con libertad de pensamiento y con criterio propio.

Debido a esa relación entre arte y cultura para configurarnos como personas, es fundamental entender la incorporación de estas expresiones artísticas en modos de educación activa que se encuentren dentro de los programas pedagógicos, formales o no formales, pero presentes en el currículo de las personas, desde la infancia, para hacer entender que su importancia en la formación de la personalidad es primordial.

Lorca decía: "Cuando no soy capaz de escribir un poema lo dibujo". Y es que dejamos de dibujar demasiado deprisa, dejamos de expresarnos en un lenguaje plástico que, sin embargo, es de vital importancia para expresarse donde la palabra no es capaz de llegar.

Hagamos una reflexión en relación con arte/ocio. Es importante entender esta distinción, ya que en los últimos años estas líneas se han diluido mucho y no podemos entender el arte, al menos en los programas políticos, la educación superior, e incluso en la

\footnotetext{
${ }^{1}$ Vamos a seguir la aproximación conceptual realizada por Gemma aguado, Anna Escofet y María José Rubio sobre el término en: Identidades femeninas en un mundo plural de Ma Elena Jaime de Pablos (Ed.) Arcibel editores, Sevilla, 2009.
} 
empresa privada, sin entender que ambas están unidas. Y necesitamos encontrar modos diversos de hacer, modos diferentes de entender la cultura, no como un negocio, no como una industria cultural, no como el mercado del arte.

Necesitamos entender la parte desinteresada de la cultura, aquella que busca precisamente esa formación integral de la persona de la que hablábamos, que es el fundamento de la pedagogía, de la creación del espíritu crítico en la persona. No aquella que se utiliza para matar el tiempo. La cultura, que es la del pueblo, es la que configura la identidad, es la que crea historia, la que entra en las biografías individuales.

En los últimos años se ha hecho un esfuerzo por mostrar a los públicos, más allá de la academia y los circuitos del arte, esa posición de la mujer con exposiciones temporales de nuestras colecciones de patrimonio histórico español. Dos buenos ejemplos de ello son los esfuerzos que ha realizado el Museo Nacional del Prado con la muestra en 2015: El arte de Clara Peeters o más recientemente en 2019 la exposición Historia de Dos Pintoras: Lavinia Fontana y Sofonisba Anguissola. En ambas exposiciones se ha trabajado en la recuperación, no sólo de obras, si no de la mano femenina que era autora de las piezas.

Observaremos, en las fichas realizadas en el estudio, las referencias comparadas de cómo se ha representado tradicionalmente a los hombres en el mundo del arte con respecto a las mujeres en una misma categoría. Pensemos en la representación de Cibeles/Neptuno como un modo de aplicación de esa perspectiva de género dentro de las artes plásticas.

No podemos dejar de citar los trabajos sobre el patrimonio cultural español de teóricas del arte como Mayayo y su Historia de mujeres, historias del arte o La mujer y la pintura del XIX español de Estrella de Diego. Ambas referencias han sido fundamentales en la elaboración de las fichas que se presentan en este artículo.

\section{Mujeres de Madrid y un recorrido artístico por su historia}

Con la intención con la que Lipovetsky reconcilia en La tercera mujer a "la mujer radicalmente nueva y a la mujer siempre repetida" (Lipovetsky, 2002, pág.12) aunamos en este estudio nuestras diez mujeres. Si pensamos en las ciudades no como un conjunto de edificios o de calles que albergan coches y otros enseres, si no que acabamos entendiendo los bares por quien los regenta, las instituciones por los trabajadores y las trabajadoras que las conforman, nos daremos cuenta de que las ciudades son al fin y al cabo las personas que las habitan.

Así podemos observar cómo las biografías de sus ciudadanos, en este caso de sus ciudadanas, se va a relacionar directamente con lo que la ciudad de Madrid va a ser. Pensemos en Manuela Malasaña o Isabel II. Hoy en día con posiciones en política también, pero no sólo, porque nos encontramos importantes papeles desarrollados por mujeres en la escuela y en otros ámbitos de la vida cotidiana de las mujeres de Madrid.

A continuación, vamos a hacer un recorrido por personajes, por mujeres que han nacido en la Comunidad de Madrid y cuyas biografías han supuesto hitos, cada una de ellas en su contexto, para la historia del territorio. 
Para la investigación se han buscado perfiles diferentes, tanto a nivel cronológico como a nivel de dedicación, tipología del retrato y grado de incidencia en la sociedad actual. Esta selección responde precisamente a motivos con una especificidad metodológica. Se han seleccionado con la intención de conseguir resultados en la línea de lo descrito en la introducción de este artículo.

Sin caer en anacronismos, sus vidas nos van a servir para poder organizar y sistematizar la información. En el proceso de la propuesta de investigación se parte de varias premisas que formulan las siguientes preguntas, bajo una serie de parámetros. En primer lugar, poner a disposición cuál es el uso del espacio público que se le concede a la mujer y cuáles son los límites entre los espacios privados y los públicos. Además, ver cómo se esclarecen debates relativos a la mujer y su configuración identitaria. Para ello se han buscado modelos temporales de mujeres y de sociedades. Este tipo de investigación ofrece una visión del conjunto, y a su vez, de los particulares de estas biografías y los momentos concretos. También ha sido capital la interpretación de las obras de arte plástico. Tal y como señala Benhabid "El sujeto situado y generalizado está heterónomamente determinado, pero a pesar de ello lucha en pos de la autonomía” (Benhabid, 2005, pág. 321-322)

Vamos a presentar a: María Guerrero, Manuela Malasaña, Isabel II, Santa María de la Cabeza, Catalina de Aragón, María de Zayas, Mํㅗ Isidra de Guzmán, Clara Campoamor, Juanita Cruz y a Cibeles.

Ya que el estudio trata de esas construcciones de lo femenino, que se encarnan en mujeres, o la idea que tenemos de mujer, pero que ésta es plural y además tiene muchas aristas, es pretendida la inclusión de figuras como la de la diosa Cibeles, que convirtiéndose en uno de los símbolos de la ciudad de Madrid, no va a corresponder a una idea biográfica concreta, pero sí que nos va a dar muchas pistas de lo que significa el imaginario común de lo femenino y de cómo se configura esta identidad, que acaba siendo parte de un pueblo.

\section{Fichas de trabajo en una investigación bajo perspectiva feminista}

A continuación, presentamos el desglose de la investigación en cada una de las figuras femeninas seleccionadas y bajo las premisas y aspectos del análisis del estudio de estos casos para comprobar la hipótesis de cómo influye la biografía particular y la construcción de las identidades femeninas en la idiosincrasia de un pueblo. Y cuáles son los puntos que continúan vigentes hoy en la conformación del espacio urbano. Los motivos de la selección realizada se conectan con una función representativa de la interdisciplinariedad del estudio en ámbitos como política, religión, literatura o cultura clásica, bañando nuestra genealogía de identidades femeninas que nos permitan una identificación y su vigencia actuales.

Los aspectos que se tratan de forma sistemática en la investigación son: una biografía seleccionada con algunos de los aspectos encontrados y que refuerzan la presencia del personaje en el estudio. Se han unificado las biografías de cada una de ellas con una serie de parámetros comunes, a saber: nombre y apellidos; fecha y lugar de nacimiento; fecha 
y lugar de fallecimiento; profesión e influencia femenina ${ }^{2}$. Una ficha técnica en la que se explican los detalles de la pieza de arte analizada. Ésta se compone de: título, autor, breve descripción, año, técnica, medidas, datos de la institución o espacio en el que se encuentra actualmente la obra. Y, por último, se presenta un comentario estético crítico en el que se enlazan los dos apartados anteriores. En esta parte se conecta al personaje con la hipótesis del estudio.

Se ha trabajado con una confluencia de disciplinas que nos permiten valorar diferentes aspectos en nuestro análisis. Desde la Historia del Arte hemos aplicado una metodología en tres niveles: de descripción pre-iconográfica, el nivel de análisis iconográfico y el nivel de análisis iconológico. En cuanto la Sociología, se han incluido diferentes elementos que sitúan el arte como fuente de análisis para enlazar el contexto de pieza y biografía con su vigencia actual. Se hace referencia también en las descripciones a los espacios físicos u otro tipo de lugares que ocupan su legado en nuestra sociedad actual. Aludimos a su situación y relación con la configuración de la ciudad de Madrid hoy.

\section{MARÍA GUERRERO}

\section{Datos biográficos}

Nombre y apellidos: María Ana de Jesús Guerrero Torija

Fecha y lugar de nacimiento: 1867, Madrid

Fecha y lugar de fallecimiento: 1928, Madrid

Profesión: Actriz

Influencia femenina: Teodora Lamadrid

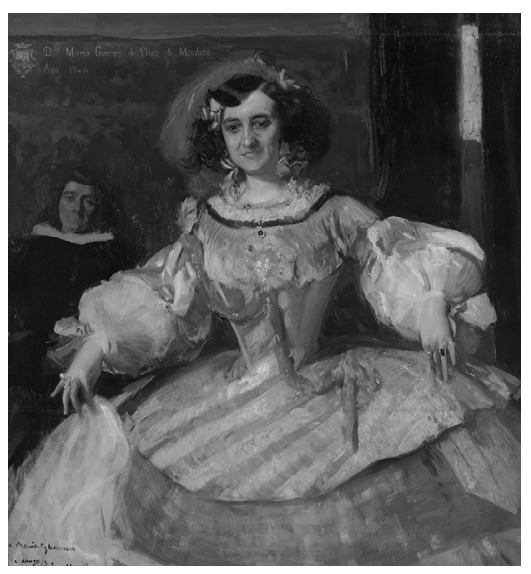

\section{Ficha técnica}

Título: "La actriz María Guerrero como «La Dama boba»"

Autor: Joaquín Sorolla

Descripción: Retrato de la actriz española María Guerrero, ataviada de "menina" para la obra teatral de Lope de Vega La Dama boba.

Año: 1906

Técnica: Óleo sobre lienzo

Medidas: $131 \mathrm{x} 120.5 \mathrm{~cm}$

Espacio: sala 60 A Museo Nacional de Prado

\footnotetext{
${ }^{2}$ En esta última línea se incluirán referencias a mujeres que hayan influido en su momento sobre la biografía de la persona o que hayan reivindicado su figura de forma posterior.
} 


\section{Descripción artística}

María Guerrero fue uno de los pilares de nuestra historia del arte en España. Madrid le ha dedicado uno de sus teatros nacionales, el Teatro María Guerrero, situado cerca de la plaza de Colón. Por un lado, es fundamental el poder de representación, la fuerza de personajes que pueden ser ejemplos para generaciones futuras. Y María lo ha sido y lo es hoy ${ }^{3}$.

En la obra pictórica, encontramos varios parámetros a analizar. En primer lugar, el hecho de que sea uno de los pintores del momento, Joaquín Sorolla, quien se haga cargo del retrato. En segundo lugar, podemos observar una parte del juego teatral con la utilización de un traje característico e identificado con España. El de las Meninas de Velázquez. Estas dos situaciones nos están ayudando en la intervención de considerar a la actriz española como un icono, una bandera de la cultura de nuestro país, en primer plano. Y, al mismo tiempo, su identificación con un modelo femenino. En este caso, con la iconografía en torno a la mujer que gracias al cuadro de Velázquez ha hecho todo un símbolo de nuestro país dicha figura. Pero para dar más fuerza a nuestros argumentos, existe un tercer nivel de lectura que refuerza la hipótesis. Éste es que el momento elegido para la representación es el de una función de otro de los clásicos de nuestro país, Lope de Vega y su dama boba ${ }^{4}$.

Hay todo un conjunto de tópicos clásicos, de una concatenación de símbolos de lo que es España a nivel cultural. Además, no podemos obviar la ejecución precisa de Sorolla en la representación de lo femenino. Nos encontramos con toda una serie de retratos de mujeres fuertes, enérgicas, con vestimenta a la vanguardia y con rostros llenos de vida. Esta es la manera en la que el pintor representaba lo femenino, y, sin duda, este cuadro es un ejemplo de ello.

A este respecto, véase la exposición realizada en el Museo Thyssen-Bornemisza al respecto de Sorolla y la moda en febrero de 2018 con la colaboración del propio Museo Sorolla y en la que se podía ver esa relación tan especial y esa visión tan importante del artista del mundo femenino. En la selección de las piezas comisariadas confirmamos la hipótesis de los modelos de representación femeninos por Joaquín Sorolla y la influencia posterior, que ha dejado su impronta en nuestras sociedades contemporáneas.

\section{MANUELA MALASAÑA}

\section{Datos biográficos}

Nombre y apellidos: Manuela Malasaña Oñoro

Fecha y lugar de nacimiento: 1791, Madrid Fecha y lugar de fallecimiento: 1808, Madrid

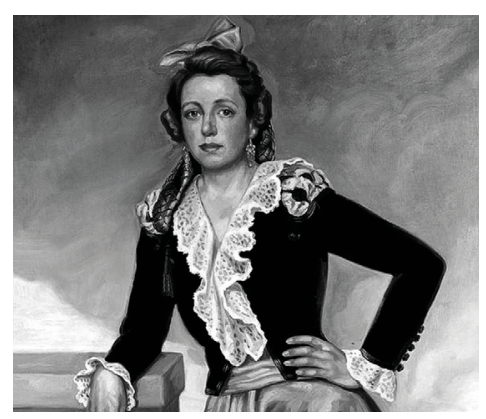

\footnotetext{
${ }^{3}$ Debemos citar a Menéndez-Onrubia, C. (2017). María Guerrero. Semblanza y época de una actriz. Conferencia en el Museo Nacional del Prado.

${ }^{4}$ Citamos el trabajo de Amezúa, J. María Guerrero en el Museo Nacional del Prado . IV Encuentro de Profesorado en Museo Nacional del Prado
} 
Profesión: costurera / heroína popular

Influencia femenina: Florencia Peyrou ${ }^{5}$

\section{Ficha técnica}

Título: "Retrato de Manuela Malasaña"

Autor: José Luis Villar y Rodríguez de Castro.

Descripción: Retrato idealizado del personaje de Manuela Malasaña

Año: 1887

Técnica: Óleo sobre lienzo

Medidas: 30,7 x 37,9 cm

Espacio: Sala de Heroínas del Museo del Ejército de Madrid.

\section{Descripción artística}

En el caso de este retrato, como bien decíamos en su ficha técnica, se trata de un retrato idealizado. Es interesante si hablamos de la creación de iconos, ya que Manuela Malasaña es un personaje, no una persona. Se va a convertir en tal por una serie de circunstancias y a una edad temprana ${ }^{6}$.

Al unirse la transformación de la persona al personaje y el momento histórico, tenemos los ingredientes de la creación de un icono. En el caso de Manuela Malasaña es clara la unión entre biografía individual e identidad colectiva.

En el retrato podemos ver que no es posible establecer una adecuación con su edad real, ya que, en el intento de ensalzarla, nos encontramos con una edad mayor de la real. Eso sí, en la imagen, hay varios factores visuales que nos van a indicar ese ensalzamiento.

En primer lugar, la posición de la figura se encuentra centrada en el encuadre, con la mirada fija en el espectador, con una disposición cercana, sea por lo postura que por ese gesto en la mirada. Además, la gama cromática es oscura. Se trata de una clave baja de la imagen, lo cual denota sobriedad. Pero al mismo tiempo es cálida. Esta combinación nos ofrece cercanía.

En cualquier caso, también esa edad excesiva, nos habla de experiencia. Hay una creación de signos de autoridad que es pretendida. Podemos concluir que está intencionalmente buscada por el artista para reforzar la idea de icono, de figura de poder, ensalzando al máximo las características que el pueblo conoce del personaje y que se acercan a la leyenda y se alejan de la persona.

Sin duda, nos encontramos ante una representación de cómo empieza a manifestarse un mito, que en este caso ha dado origen a mucha iconografía y literatura, que ha sido expresado como romance. Esta figura está presente hoy en la ciudad de Madrid en una calle y dando nombre a un barrio, que además no está considerado como tal por las directri-

\footnotetext{
${ }^{5}$ Autora de Manuela Malasaña. De joven costurera a mito madrileño en Heroínas y compatriotas, mujeres de1808. 2009.

${ }^{6}$ Aludimos a Palmer, M. D. C. S. (2008). Manuela Malasaña Oñoro, la heroína accidental. Ilustración de Madrid: revista trimestral de la cultura matritense, (7), 53-56.
} 
ces municipales, pero que ha sido adoptado como tal de forma popular. En su vida actual, se perfila como un conjunto de calles con vocación artística y una demografía principalmente joven tal y como muestran las estadísticas que ofrece el Ayuntamiento de Madrid ${ }^{7}$.

Esta asociación de características es fundamental para entender las uniones entre las personas anónimas que se van a convertir en personajes públicos unidos al territorio o a la historia de un espacio y cómo además estos personajes acaban convirtiéndose en iconos, como la joven Manuela Malasaña.

\section{ISABEL II}

\section{Datos biográficos}

Nombre y apellidos: Isabel II de España

Fecha y lugar de nacimiento: 1830, Madrid

Fecha y lugar de fallecimiento: 1904, París

Profesión: Reina de España entre 1833 y 1868

Influencia femenina: María Cristina de Borbón-

Dos Sicilias

\section{Ficha técnica}

Título: "Isabel II"

Autor: Atribuido a Lozano Sirgo, Isidoro Santos.

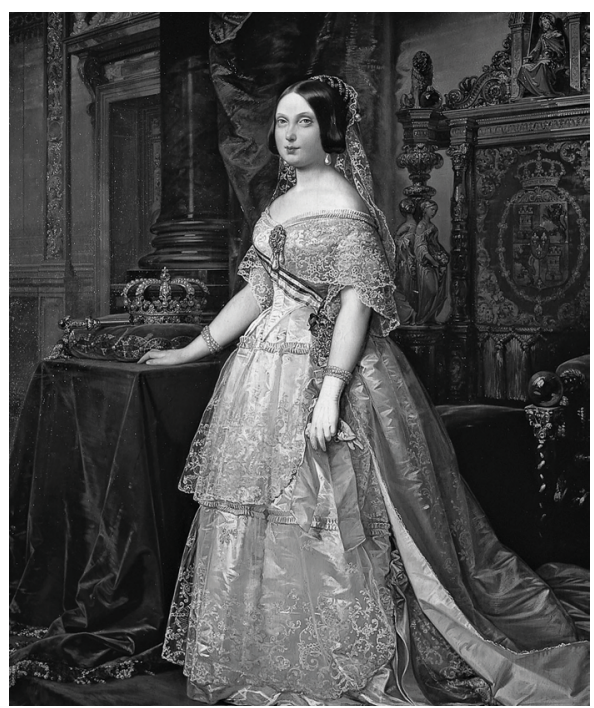

Descripción: Retrato oficial de la Reina Isabel II del cual se conservan diversas copias en otros Museos de Titularidad Estatal, como el Museo Naval.

Año: 1848

Técnica: Óleo sobre lienzo

Medidas: $224 \times 149 \mathrm{~cm}$

Espacio: Colección del Museo Nacional del Prado

\section{Descripción artística}

En el caso de Isabel II, nos encontramos con una reina, una figura que por excelencia no tiene poder de decisión sobre su biografía, cuyos pasos están programados desde su nacimiento. En el de la chata, como se la conocía en Madrid, tenemos una infancia, una adolescencia y una juventud que están fuera de su alcance en todos los sentidos ${ }^{8}$.

\footnotetext{
https://www.madrid.es/portales/munimadrid/es/Inicio/El-Ayuntamiento/Estadistica/Distritos-en-cifras/Distritos-en-cifras-Informacion-de-Barrios-/?vgnextfmt=default\&vgnextoid=0e9bcc2419cdd410VgnVCM2000000c205a0aRC RD\&vgnextchannel=27002d05cb71b310VgnVCM1000000b205a0aRCRD Consultado en noviembre 2020.

${ }^{8}$ Hacemos referencia a una perspectiva feminista con Burdiel, I. (2011). Isabel II: una biografía (1830-1904). Barcelona: Taurus.
} 
Muchas veces hay distorsiones con las personas y los personajes que interpretan y en muchas ocasiones hay evoluciones en las figuras públicas que se van transformando y evolucionando según se van desarrollando las circunstancias en las que se ven envueltos.

Éste es el caso de Isabel II, de la cual, si nos fijamos en la iconografía que viene representada en la pintura que hemos tomado como ejemplo, vamos a poder ver una reina joven, adolescente, que es el centro de la composición. Tenemos que ver su postura relajada, así como todos los elementos que la acompañan.

Debemos destacar, tal y como hemos señalado en la descripción, que se trata de un retrato oficial. Tal título hace que aquí el arte se ponga al servicio de la historia. El arte se convierte en una perfecta fuente de análisis social que busca comunicar un mensaje a través de la imagen y los atributos que en ella aparecen.

En esta pintura es muy importante la gama de colores escogida, así como la iluminación. El blanco y el azul de la vestimenta de la figura contrastan con los tonos rojos y amarronados del fondo. Entre los dos se genera una contraposición que resalta aún más la figura de la reina con una piel blanca y una mirada tranquila. Se trata de una posición serena que, a su vez, interpela directamente al espectador.

\section{SANTA MARÍA DE LA CABEZA}

\section{Datos biográficos}

Nombre y apellidos: María Toribia

Fecha y lugar de nacimiento: inicios del siglo XII, Caraquiz

Fecha y lugar de fallecimiento: 1175, Madrid

Profesión: Campesina / santa

Influencia femenina: Teresa Díaz Díaz ${ }^{9}$

\section{Ficha técnica}

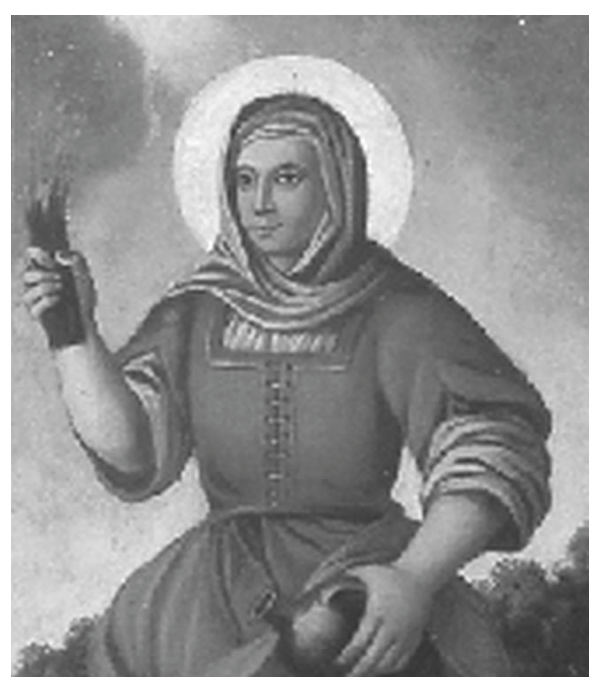

Título: "Santa María de la Cabeza"

Autor: Desconocido

Descripción: Retrato de la santa con los atributos propios de su iconografía.

Año: Siglo XVIII

Técnica: Óleo

Medidas: 1,10 x 0,48 m.

Espacio: Museo Municipal de San Isidro (Madrid)

\footnotetext{
${ }^{9}$ Autora Díaz, T. D. (2008). Santa María de la Cabeza, única santa nacida en la provincia de Guadalajara (Caraquiz, Uceda), de origen judeoconverso. En El culto a los santos: cofradías, devoción, fiestas y arte (pp. 637-654). Ediciones Escurialenses.
} 


\section{Descripción artística}

La imagen elegida para la representación de este personaje ha sido una elección complicada. Hemos encontrado diferentes piezas que la representan en sus dos facetas: como campesina y como santa. Curiosamente en España sólo encontramos representaciones de su segunda faceta. Especialmente pinturas y esculturas que se ponen en relación con otras biografías con las que se encuentra unida su figura. Éstas son: su marido, San Isidro; y su hijo, San Illán. Por lo que conocemos de su biografía, sabemos que ese aire de misticismo que envuelve su figura se ve reflejado en esas imágenes alegóricas e idealizadas que representan a Santa María de la Cabeza. Lo hacen o bien junto a su marido San Isidro o en solitario, pero siempre con los atributos que nos permiten distinguirla. Siguiendo a Molledo ${ }^{10}$ esta iconografía está constituida por una alcuza de aceite en su mano izquierda (que suele acompañar dentro de la iconografía tradicional al complemento de una aguijada en manos de San Isidro), los ropajes típicos de la época y, en la mano derecha, el trigo, que sin duda, alude al milagro del molino de harina sobre el río Jarama.

En este caso, en la pintura seleccionada nos encontramos con una posición central de la figura, con una postura idealizada. En la imagen la gama cromática está llena de tonos terrosos, que acompañan a esa cotidianidad y calidez. Ambas características de una atmósfera de cercanía con el espectador.

En otras representaciones encontramos elementos diferentes, pero que siempre hacen referencia a las dos vertientes de su biografía: su trabajo en el campo y su santidad. El primero es generalmente un instrumento de labor como un rastrillo o cualquier otro útil de trabajo en el campo, que nos habla precisamente de lo mundano y de la procedencia y vida de la Santa. En segundo lugar, podemos encontrar elementos como un rosario, el cual nos habla de ese carácter místico, pero integrado de una forma muy adecuada en la vida campestre que se nos presenta en la mayoría de sus representaciones.

Este tipo de representaciones tienen interés ya que nos ofrecen una vertiente distinta. Aunque, como decíamos al inicio, en España encontramos imágenes que representan sólo la parte religiosa, relegando a algún símbolo la representación de la vida mundana de la santa. Este hecho nos muestra el tratamiento histórico que se le ha dado a la figura femenina con representaciones de la iconografía católica utilizando la imagen de la mujer y, por tanto, de su construcción identitaria, como madre y esposa. Como una figura idealizada que se desapega de la cotidianidad en la mayoría de sus versiones iconográficas. Las representaciones artísticas más apegadas a lo real constituyen un modo diferente al que estamos acostumbrados desde la iconografía cristiana en la representación de lo femenino, como puede ser el ejemplo de las vírgenes u otras santas que se muestran de un modo excesivamente idealizado, alejado de la realidad.

En el caso de Santa María de la Cabeza también nos encontramos con parte a su homenaje no sólo en la festividad del 9 de septiembre en el santoral, sino que hay un Paseo y

\footnotetext{
${ }^{10}$ Molledo, J. M. S. (2009) Iconografía de San Isidro Labrador y Santa María de la Cabeza. Pasos de arte y cultura, (9), 66-68.
} 
una Glorieta con su nombre y nos encontramos con iconografía suya en la capital, en unas esculturas junto a su marido San Isidro Labrador. De alguna forma, como ocurre con otras de las mujeres seleccionadas para el estudio, encontramos su impronta y su vigencia en la configuración actual de la ciudad de Madrid.

\section{CATALINA DE ARAGÓN}

\section{Datos biográficos}

Nombre y apellidos: Catalina de Aragón y Castilla o Catalina de Trastámara y Trastámara

Fecha y lugar de nacimiento: 1485, Alcalá de Henares Fecha y lugar de fallecimiento: 1536, Castillo de Kimbolton

Profesión: Reina consorte de Inglaterra de 1509 a 1533

Influencia femenina: Isabel I de Castilla

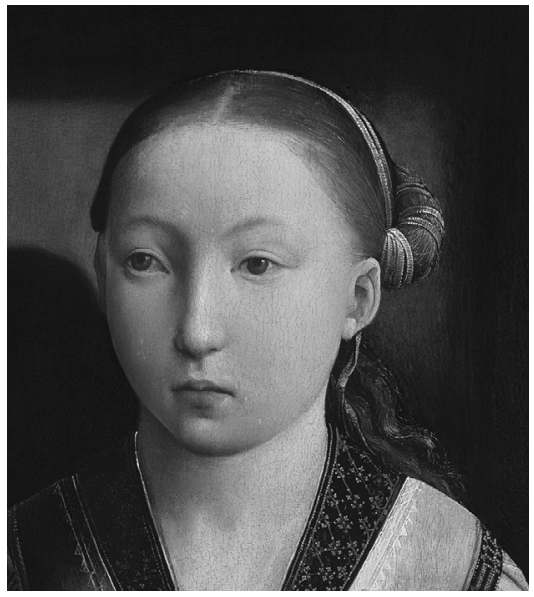

\section{Ficha técnica}

Título: "Retrato de una infanta. Catalina de Aragón"

Autor: Juan de Flandes

Descripción: Retrato de la infanta a una edad muy temprana.

Año: 1496

Técnica: Óleo sobre tabla

Medidas: $31,5 \times 21,7 \mathrm{~cm}$

Espacio: Museo Nacional Thyssen-Bornemisza.

\section{Descripción artística}

Si nos detenemos en la biografía de Catalina de Aragón, nos encontramos un nacimiento casi por accidente en Alcalá de Henares, en una biografía que va a estar plagada de destinos que no eran los que se esperaban ${ }^{11}$. Y que, a su vez, son imposibles de controlar por parte de la persona que los vive, ya que se encuentran programados de antemano.

En el retrato del museo Thyssen nos encontramos con la niñez, con la representación de un rostro de una forma muy cercana al espectador. El tamaño del cuerpo que, en este caso, nos dice algo, tiene un tamaño pequeño, que precisamente permite esa cercanía que se ofrece al público.

${ }^{11}$ Seguimos a Earenfight, T. M. (2016). Raising Infanta Catalina de Aragón to be Catherine, Queen of England de Catalina de Aragón a Catalina de Inglaterra. La educación de una infanta. Anuario de Estudios Medievales, 46(1), 417-443. 
Aunque la figura es central y cercana, como apuntábamos, no es desafiante, el retrato no dirige sus ojos al público, si no que desvía la mirada, la postura no es inquietante, pero podemos decir que es seria y podemos verla llena de pensamientos.

Aquí también nos encontramos con un elemento que sostiene en su mano. Esta iconografía empieza a ofrecer datos al espectador. Debemos aludir a un uso muy inteligente del color que se presenta armónico entre el color blanco azulado del principal, así como los tonos pajizos del resto de los detalles.

Ésta es una manera de presentar la construcción de la feminidad encarnado por parte de la Casa Real Española y a una edad temprana ${ }^{12}$.

Es interesante la parte relacionada con la educación y la instrucción de los miembros de las casas reales europeas. De lo que se consideraba necesario que una mujer debía saber, que por aquel entonces se limitaba a saber leer, escribir y bordar. Si bien es cierto, que dependiendo del destino al que estuviera abocada una mujer de la familia real, podía aprender otras cosas relacionadas con el ejército, la política o la economía. Como fue el caso de su madre Isabel, que al no estar destinada a ser reina tuvo que aprender cuando la necesidad obligó a ello. En el caso de Catalina ella fue la menor de las hijas de los Reyes Católicos. Bien es cierto que sería una mecenas del Arte y estuvo cercana a figuras intelectuales de la época como Erasmo de Rotterdam o Tomás Moro ${ }^{13}$.

\section{MARÍA DE ZAYAS Y SOTOMAYOR}

\section{Datos biográficos}

Nombre y apellidos: María de Zayas y Sotomayor

Fecha y lugar de nacimiento: 1590, Madrid

Fecha y lugar de fallecimiento: 1647, Madrid

Profesión: escritora

Influencia femenina: Ana Caro de Mallén

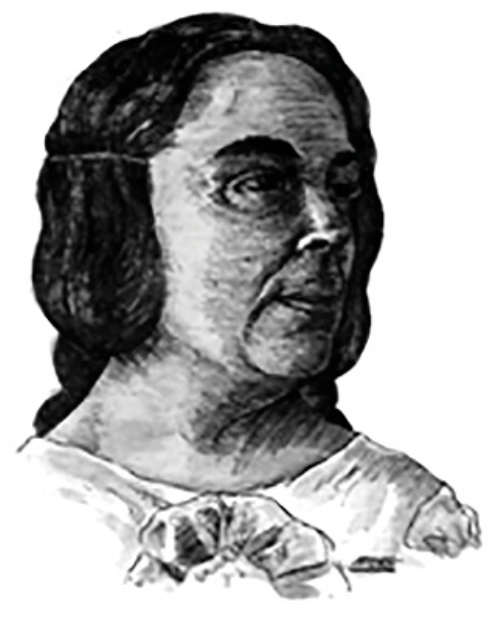

Ficha técnica

*No existen datos específicos sobre el bosquejo, que aparece en color y en blanco y negro en diferentes fuentes y es la única imagen que poseemos en la actualidad que hace referencia a la autora. Se expondrá en la Biblioteca Nacional Española en el año 2013 con motivo del festival Ellas crean.

\footnotetext{
${ }^{12}$ Citamos el trabajo desde una perspectiva feminista sobre la figura del personaje de De Arteaga, A. (2018). Catalina de Aragón: reina de Inglaterra. La Esfera de los Libros.

${ }^{13}$ De la Plata, V. M. M. (2005) Mujeres renacentistas en la corte de Isabel la Católica:[Beatriz de Bobadilla, Beatriz Galindo, Lucía de Medrano, Beatriz de Silva, Catalina de Aragón, María Pacheco] (Vol. 14). Editorial Castalia.
} 


\section{Descripción artística}

Este retrato, del que no he podido encontrar datos específicos, es la imagen que ha llegado hasta nosotros de María de Zayas, se trata de un grabado, de un bosquejo que encontramos coloreado y en otras parte, en blanco y negro, que representa el rostro de la escritora del Siglo de Oro español ${ }^{14}$.

Se trata de una figura, de una cabeza que está dispuesta en el soporte sin ningún tipo de referencias, no hay ningún fondo, ni tampoco una unión al resto del cuerpo. Es un primer plano con unas proporciones que a priori no nos parecen adecuadas.

Es una representación muy de la época, con una gama cromática que está compensada en cuanto a tonalidades. La cabeza está en una posición de tres cuartos y no hay una interpelación directa con el espectador, ya que la mirada no es frontal. Hay parte del ropaje superior y un recogido de los cabellos.

Tenemos pocos datos, pero podemos advertir la época y la fortaleza con la poca información que nos facilita la imagen. Esta falta de información también es un síntoma de cómo se ha borrado la identidad, al menos visual, de este personaje femenino en relación a otros personajes masculinos del mismo momento. Hablamos de un Siglo de Oro en el que priman las voces de literatos varones. Este personaje femenino forma parte del análisis del estudio de caso, precisamente para mostrar esa invisibilidad que tanto se acusa en la edad contemporánea en relación con la presencia de la mujer en la vida pública y en las artes.

Es fundamental reivindicar y explorar figuras femeninas de la Historia, que la han construido desde el Arte, o desde otras disciplinas, para entender esta versión que también era parte y que nos cuenta la vida con una mirada nueva, diferente y necesaria para entender la Historia de una forma adecuada ${ }^{15}$.

\section{MARÍA ISIDRA DE GUZMÁN Y DE LA CERDA}

\section{Datos biográficos}

Nombre y apellidos: Maㅗ Isidra Quintina de Guzmán y de la Cerda

Fecha y lugar de nacimiento: 1767, Madrid Fecha y lugar de fallecimiento: 1803, Córdoba

Profesión: Académica Honoraria de la Lengua Influencia femenina: Paloma Fernández Quintanilla ${ }^{16}$

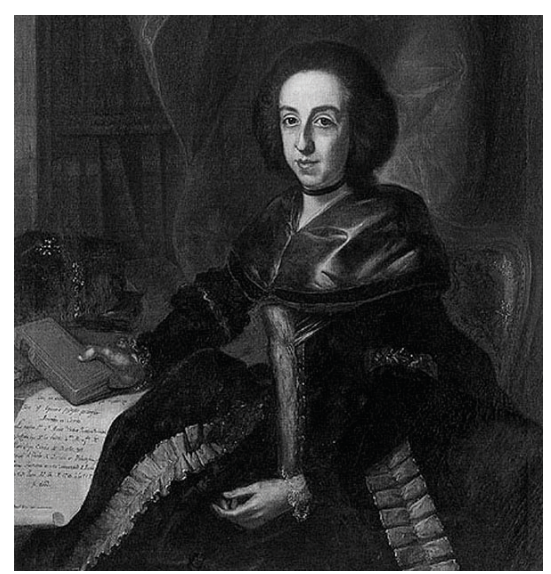

\footnotetext{
${ }^{14}$ Desde una perspectiva feminista citamos a Rudat, E. M. K. (1975). Ilusión y desengaño: el feminismo barroco de María de Zayas y Sotomayor. Letras femeninas, 1(1), 27-43.

${ }^{15}$ Gorgas Berges, Ana Isabel (2019) Pactos entre mujeres: Ecos soportales en la narrativa de María de Zayas y Sotomayor. Madrid: Universidad Carlos III de Madrid.

${ }^{16}$ Fernández Quintanilla, P. (1979) Una española ilustrada: Doña María Isidra Quintina de Guzmán y de la Cerda. Universidad de Salamanca, Revista Tiempo de Historia, no0.
} 


\section{Ficha técnica}

Título: "María Isidra de Guzmán y de la Cerda"

Autor: Joaquín Inma y Ainsa (1736-1811)

Descripción: Retrato de la aristócrata española (1768-1803)

Año: 1785

Técnica: Óleo sobre tela

Medidas: $106 \times 85 \mathrm{~cm}$

Espacio: Facultad de Filosofía y Letras.

\section{Descripción artística}

Sus libros y el negro son los que encontramos como elementos principales de la imagen. Nos disponemos ante un retrato que nos recuerda mucho al tipo de retrato fotográfico que vendrá algún tiempo después.

La figura se presenta centrada, en una posición relajada, con esos libros que dan cuenta de lo importante que es el estudio, que hacen uso de la inteligencia de la retratada ${ }^{17}$. Y el color negro de su traje, con sobriedad y haciendo que destaquen todos los otros elementos representados en el cuadro en tonos rojizos. Como ya hemos visto en otras obras, este tipo de tonalidades aportan calidez a la imagen y generan empatía y cercanía con el espectador. La combinación con el negro ayuda a otorgar sobriedad a la imagen en su conjunto.

Nos encontramos con una posición sedente, pero erguida, recta, la manera en la que coge el libro, con decisión. Nos desvela un carácter fuerte en su mirada, serena, pero con decisión. Todas las características que han llegado a nosotros, son transmitidas tal y como se nos han presentado.

En este caso nos encontramos con la experiencia, con la ruptura de las barreras, con ideas que se trasmiten con solo mirar la imagen que representan una parte de lo que hemos considerado en la construcción de lo femenino, lo que supone el campo de la inteligencia. Se trata de una representación clásica, académica. Y, además, incluso hoy, permanente dentro de ese mundo de la academia en su espacio dentro de la Facultad.

De este modo, la figura que se nos presenta, y que es la que ha dejado la Historia, es la de una mujer que era buena madre y esposa, que además tuvo una vida profesional ejemplar, sin dejar por ello de generar ciertas controversias su éxito, sobre todo en la época.

Sin duda rompió barreras para las mujeres, que como comentábamos antes, incluso hoy casi tres siglos después, seguimos teniéndolo difícil para poder acceder a ciertos espacios que tradicionalmente han sido reservados a los hombres.

También en las figuras femeninas de personajes históricos hemos incluido la suya como caso de estudio. Para demostrar ese olvido no justificable durante los siglos posteriores a su muerte.

\footnotetext{
${ }^{17}$ Ferrandez, V. M. P. Y. (2012) María Isidra de Guzmán y de la Cerda 1768-1803: la primera mujer doctora en Filosofía y Humanidades. Hidalgos: la revista de la Real Asociación de Hidalgos de España, (529), 57-60. 


\section{CLARA CAMPOAMOR}

\section{Datos biográficos}

Nombre y apellidos: Clara Campoamor Rodríguez

Fecha y lugar de nacimiento: 1888, Madrid

Fecha y lugar de fallecimiento: 1972, Lausana

Profesión: abogada, escritora y política

Influencia femenina: Victoria Kent

\section{Ficha técnica}

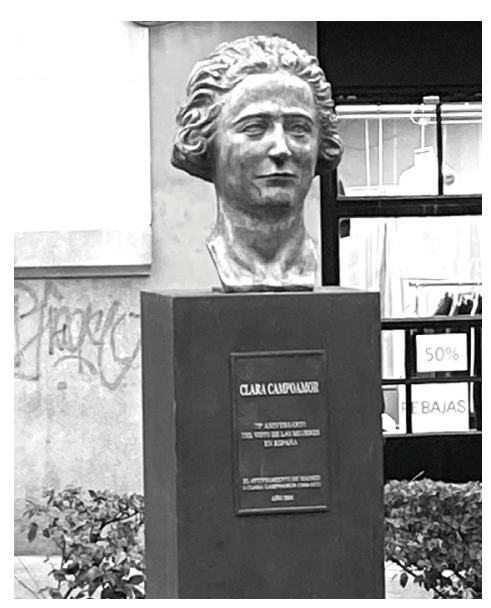

Título: Clara Campoamor

Autor: Escultor vasco Lucas Alcalde

Descripción: escultura que representa el busto de la figura de Clara Campoamor

Año: 2006 / reposición tras su desaparición en 2016

Técnica: Escultura en bronce

Medidas: 178 × 65 x $50 \mathrm{~cm}$

Espacio: Plaza de Guardias Corps, muy cerca de Princesa (Metros Plaza de España o Noviciado)

\section{Descripción artística}

La escultura se realiza en 2006 para celebrar el 75 aniversario del voto femenino español. para la conmemoración del setenta y cinco aniversario del voto de la mujer en España. Está hecha en bronce y tiene un pedestal de acero con una placa explicativa.

Es importante que los monumentos que hagamos en las ciudades digan algo de quienes somos y de quienes hemos sido, que recuerden a los que nos han ayudado a construirnos. Y este es el caso de una escultura como la de Clara Campoamor, además de poder recordarnos a la política y escritora española, también lo hace de uno de los mejores modos posibles, como la conmemoración de algo que debemos tener presente. Se trata del voto de la mujer y cómo debemos seguir luchando y pelear por nuestros derechos de igualdad, en nuestra sociedad actual y en las que les dejaremos a nuestros hijos.

La estatua está situada cerca del Centro Cultural Conde Duque y el Museo de Arte Contemporáneo del Ayuntamiento de Madrid. Es interesante hacer notar tanto la reivindicación de la figura como el hecho de su sustracción después de diez años de ser parte del paisaje urbano del espacio en el que se situaba. Así como la decisión política de su reposición con las mismas coordenadas geográficas.

Clara Campoamor es uno de los casos fragantes de la Historia reciente de nuestro país. Fue una de las voces que luchó por el voto femenino ${ }^{18}$. Siempre estamos en posición de reivindicar de la mano de nuestras mujeres como en el caso de Campoamor en las

\footnotetext{
${ }^{18}$ Viedma García, María (2019) Clara Campoamor, la mujer inapropiable en Sur: Revista de literatura no 13.
} 
diferencias entre hombres y mujeres, que por desgracia siguen vigentes. La explicación, para poder entender el por qué, pero desde luego, para no poder comprender los motivos, porque son incomprensibles, es el miedo. Miedo al poder de las mujeres. Miedo a sentirse inferiores y tener que buscar explicaciones físicas que no puedan ser rebatidas de otro modo. Y al mismo tiempo es miedo, que no sólo lo hemos encontrado en las construcciones de lo femenino, lo hemos encontrado también en los ataques a colectivos y etnias.

¡Las mujeres! ¿Cómo puede decirse que cuando las mujeres den señales de vida por la República se les concederá como premio el derecho a votar? ¿Es que no han luchado las mujeres por la República? ¿Es que al hablar con elogio de las mujeres obreras y de las mujeres universitarias no está cantando su capacidad? Además, al hablar de las mujeres obreras y universitarias, $¿$ se va a ignorar a todas las que no pertenecen a una clase ni a la otra? ¿No sufren éstas las consecuencias de la legislación? ¿No pagan los impuestos para sostener al Estado en la misma forma que las otras y que los varones? ¿No refluye sobre ellas toda la consecuencia de la legislación que se elabora aquí para los dos sexos, pero solamente dirigida y matizada por uno? ¿Cómo puede decirse que la mujer no ha luchado y que necesita una época, largos años de República, para demostrar su capacidad? Y ¿por qué no los hombres? ¿Por qué el hombre, al advenimiento de la República, ha de tener sus derechos y han de ponerse en un lazareto los de la mujer?

Yo, señores diputados, me siento ciudadano antes que mujer, y considero que sería un profundo error político dejar a la mujer al margen de ese derecho, a la mujer que espera y confía en vosotros; a la mujer que, como ocurrió con otras fuerzas nuevas en la revolución francesa, será indiscutiblemente una nueva fuerza que se incorpora al derecho y no hay, sino que empujarla a que siga su camino.

No dejéis a la mujer que, si es regresiva, piense que su esperanza estuvo en la dictadura; no dejéis a la mujer que piense, si es avanzada, que su esperanza de igualdad está en el comunismo. No cometáis, señores diputados, ese error político de gravísimas consecuencias. Salváis a la República, ayudáis a la República atrayéndoos y sumándoos esa fuerza que espera ansiosa el momento de su redención19.

\section{JUANITA CRUZ}

\section{Datos biográficos}

Nombre y apellidos: Juana Cruz de la Casa

Fecha y lugar de nacimiento: 1917, Madrid

Fecha y lugar de fallecimiento: 1981, Madrid

Profesión: torera

Influencia femenina: Sarah Pink ${ }^{20}$

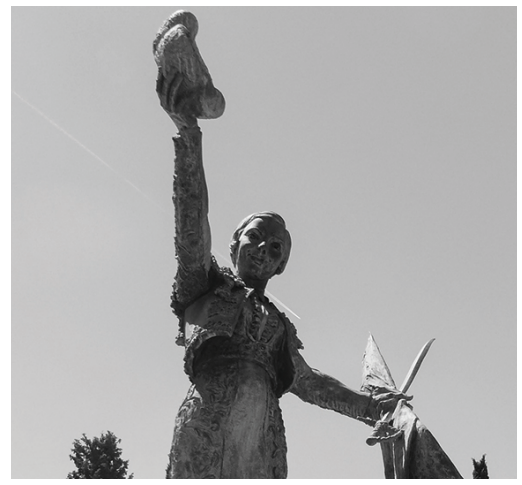

\footnotetext{
${ }^{19}$ Consultado en: https://elpais.com/sociedad/2006/10/01/actualidad/1159653602_850215.html

${ }^{20}$ Pink, Sarah (2020) Women and Bullfighting. Gender, Sex and the Consumption of Tradition. Neva York: Routledge.
} 


\section{Ficha técnica}

Título: Retrato de Juanita Cruz

Autor: Luis Sanguino

Descripción: Escultura realizada para la tumba

del personaje femenino.

Año: 1981

Técnica: Escultura en Bronce / Piedra

Medidas: 200x100x70 cm

Espacio: Tumba de Juana Cruz en el Cementerio

de la Almudena de Madrid

\section{Descripción artística}

Juana Cruz, que pasaría a ser conocida como Juanita Cruz es la torera española que vino a revolucionar el toreo femenino español.

Durante la Feria de San Isidro en el año 1981, Juanita Cruz fallecía. Esta escultura es parte de su mausoleo en el Cementerio de la Almudena. En ella nos encontramos con una escultura a tamaño natural en el que la torera está realizando un brindis, y en su mano encontramos una muleta. En su epitafio, donde aparece la descripción en piedra de la pieza leemos: "A pesar del daño que me hicieron en mi patria los responsables de la mediocridad del toreo de 1940 a 1950, brindo por España."

Como decíamos, se puede ver el resentimiento, pero también la cercanía por la patria. Ese amor-odio que muchos españoles han vivido con su país es patente en esta mujer, que siendo pionera en el mundo del toreo tuvo que exiliarse, tuvo que adaptarse a conocer nuevos mundos y que, por suerte, pudo volver a su tierra natal, aunque no para volver a la plaza de toros. Esta es una característica que ya encontrábamos con María Guerrero. Enlaza con un sesgo muy entroncado en la sociedad española, tanto de la época del personaje como de la actual. Podemos hablar de un carácter vigente que conecta de forma precisa pasado y presente.

\section{CIBELES}

\section{Datos biográficos}

Nombre y apellidos: Cibeles

Fecha y lugar de nacimiento: origen griego y frigio

Fecha y lugar de fallecimiento: -

Profesión: cultura clásica

Influencia femenina: Alfia Leiva del Valle ${ }^{21}$

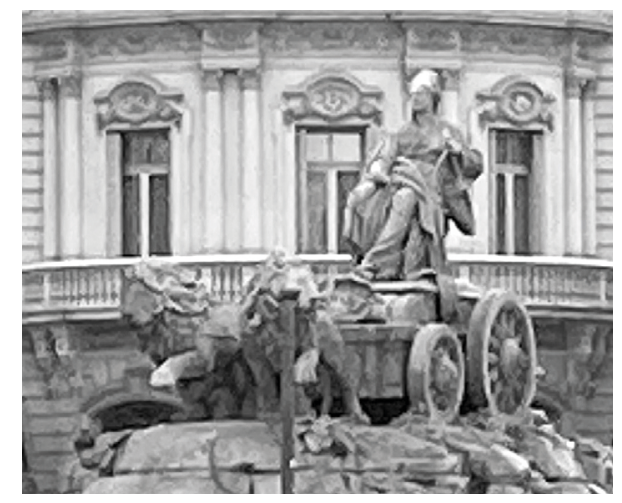

\footnotetext{
${ }^{21}$ Autora de Diosas primigenias, sus mitos, estática e influencia en las sociedades hipes-modernas líquidas. Disponible en: http://hdl.handle.net/10251/156046
} 


\section{Ficha técnica}

Título: Cibeles

Autores: Roberto Michel y Francisco Gutiérrez Arribas

Descripción: Escultura de la diosa situada en un carruaje tirado por leones en una fuente. Año: 1777-1782

Dimensiones: $5,5 \times 4,7 \times 12,5 \mathrm{~m}$

Técnica: Escultura en mármol.

Espacio: Plaza de la Cibeles de Madrid

\section{Descripción artistica}

Por último, la diosa Cibeles, esa fuente que se encontraba dentro de los planes de reforma de la ciudad que se realizaron durante el reinado de Carlos III, y que se ha convertido hoy en todo un símbolo de Madrid.

Madrid está representada por una diosa cuya procedencia es Asia Menor, que es identificada con Deméter porque comparte con ella ser una diosa de la fecundidad y también se relaciona con la protección a la agricultura.

Es importante que no perdamos estos símbolos, que fomentemos su cuidado, y que podamos seguir reivindicarlos y mirándolos para otorgarles la responsabilidad de sostenernos y para que nosotros podamos seguir identificándonos con ellos, dentro y fuera de lo que conforma la ciudad, en este caso Cibeles y Madrid.

La leyenda que proviene de la diosa frigia posee unas características concretas que hereda nuestra figura. Pero según se van sucediendo las décadas, estos significados van cambiando, adaptándose y este es el caso de Cibeles, la de Madrid, que va creando historia según se van haciendo usos del espacio público, según se van tomando los símbolos para la representación y para la dotación de significados y que no cejan en su empeño por mantener la esencia de lo que son y por mirar cómo vamos creciendo como sociedad. Esta pieza también ha sufrido actos de vandalismo, tal y como hemos visto con el robo de la escultura de Campoamor, y ha sido restaurada por su valor.

Hemos querido incluir a la diosa Cibeles, o más concretamente, hemos introducido la escultura que se inserta en la plaza que lleva su nombre, por haberse convertido en un símbolo de la ciudad. En ser parte de la iconografía urbana y de ella imagen de Madrid, y esto, encarnado por una alegoría que representa una construcción femenina.

Se trata de un conjunto monumental enmarcado dentro del estilo del neoclasicismo que está compuesto por la reforma que se realiza en la ciudad de Madrid conocida como "El salón del Prado" y que se llevó a cabo desde 1775 y hasta 1782. El arquitecto José de Hermosilla y Sandoval fue el encargado de realizar dicha reforma por el rey Carlos III. Además de la Cibeles estaban proyectadas las fuentes de Neptuno y la de Apolo. 


\section{Las identidades femeninas configuradas en los espacios de la ciudad de Madrid}

Vamos a presentar las conclusiones sobre el análisis de caso de la investigación que hemos desarrollado en este artículo. El estudio realizado aporta una visión de la ciudad que se conforma a través de una selección de mujeres como configuradas de la historia de Madrid. Se ha relacionado la construcción de las identidades femeninas con la definición de una sociedad a través del arte como herramienta de análisis.

El legado que han dejado las biografías de las mujeres en la ciudad, se puede ver representado, a través del arte, en las manifestaciones que hemos presentado en este artículo. Pero, al mismo tiempo, han ido construyendo parte de la identidad de la ciudad, de un modo tangible, con sus nombres en plazas, calles y barrios.

A través de sus representaciones artísticas en estatuas y pinturas, vemos encarnados diferentes modelos de mujer encarnados por ellas en ámbitos muy diferentes como las artes escénicas, la política o llegando a convertirse en símbolo de la capital.

Todas las representaciones artísticas seleccionadas para el análisis pueden tener una comparación con el modo de representar las masculinidades de sus coetáneos y que, sin duda, ofrecen una visión que introduce la perspectiva de género dentro del campo del retrato artístico. En algunas ocasiones podemos observar cómo hay mímesis en la representación. Es decir, se busca la imitación de la representación de las identidades masculinas en las femeninas. Es el caso de la imagen de Ma Isidra de Guzmán que, sin embargo, necesita sostener el libro para hacer referencia a su relación con el estudio. En otro grupo encontramos que se establecen diferencias entre la representación de lo masculino y lo femenino con una exaltación de la belleza de lo segundo. El caso de María Guerrero vista por Sorolla en la encarnación de la tradición española. 0 también perteneciente a este grupo el retrato de Manuela Malasaña que nos remite directamente a una heroína popular, pero en una actitud cotidiana e idealizada de la persona para convertirse en personaje. También podemos observar cómo se busca la omisión de atributos y puesta en valor de otros, precisamente para ensalzar la figura. Es el caso del retrato de Clara Campoamor, donde sólo vemos la representación de la cabeza. Hecho que observamos a su vez en el inquietante rostro infantil de Catalina de Aragón. La representación del poder en las identidades femeninas viene acompañada de una de las características que se atribuyen a las mujeres: la tranquilidad, que muchas veces se asimila en una sonrisa, en una posición sedente o en una inocencia pretendida. En este caso se encuentran tanto el retrato de Isabel II, que ha buscado apaciguar en su representación oficial el papel social que le ha otorgado la Historia. El poder de los monarcas varones, sin embargo, se representa con una actitud muy diferente: bien a caballo, en la batalla o, desde luego, con altivez. Y, en este grupo también incluimos la representación de la diosa Cibeles, que se encuentra en una escultura sedente, con actitud tranquila. Esto puede contraponerse a la representación masculina de otro dios, Neptuno. Éste representado en un carro, al igual que Cibeles, posee, en cambio, una actitud muy diferente. El caso de María de Zayas nos ayuda a comprender la invisibilidad. Contamos con un retrato realizado a través de un dibujo, la más efímera de las artes. Y que, además, ha puesto en duda la existencia real de la persona, convirtiendo directamente en 
un mito al personaje. Misticismo también es el que ha rodeado la figura de Santa María de la Cabeza, que se representa de forma idealizada por su marcado carácter religioso. Y, por último, Juanita Cruz, en un mundo absolutamente representado por figuras masculinas y que se ha adoptado en la vestimenta a los estereotipos asociados a la identidad femenina, la falda de un traje de luces.

Para poder conectar las biografías con su vigencia actual, debemos hacer referencia a la relación entre la ciudad y la Posmodernidad haciendo la siguiente reflexión. La ciudad en nuestros días se convierte en el eje principal sobre el que entender la estructura de lo urbano y su organización en torno a los modos de atender la ciudad. En concreto nos concentramos en la ciudad de Madrid como escenario en el que transcurre la representación de las biografías de las mujeres del estudio. Debemos recuperar a Marian López:

La posmodernidad se caracteriza, además, por un elemento fundamental: la desaparición del sentido de la historia. El sistema social contemporáneo ha comenzado a perder la capacidad para retener su propio pasado. Ha comenzado a vivir un presente perpetuo. Desaparecido el hilo conductor de la historia, la "Historia" con mayúsculas, salen a la luz las "otras" historias, a través de las otras culturas. El reconocimiento de la otredad permite la descentralización de los cánones y su pluralización. Esto lleva al cuestionamiento del concepto de sujeto en su término moderno, del sujeto individual, creador de su propia historia y emancipado. La pérdida del concepto de sujeto como tal y la desaparición de la historia como eje lógico que explica el devenir de la sociedad real lleva a la desconstrucción de tales conceptos. Y es ahí donde las teorías feministas encuentran un eco en el pensamiento. Desde su otredad reivindican y cuestionan el sujeto tradicional ${ }^{22}$.

Acercándonos a los Espacios Intermedios veremos el paso del espacio escénico a éstos. Se trata de poder establecer una relación directa entre los lugares de la ciudad y la cultura que en estos espacios se desarrolla. Esta idea conecta con una ecología de lo urbano que va a permitir establecer cartografías de la ciudad, como modo de trandisciplinaridad y como hibridación en los lenguajes contemporáneos. Podemos observar cómo al trabajar en colaboración entre instituciones y crear un diálogo entre las mismas podemos establecer un análisis más completo acerca del contexto en el que se desarrolla la vivencia de la cultura y la construcción de identidades locales a través de ella.

Tal y como describe Pavis en su diccionario teatral el espacio escénico es "el espacio real del escenario donde se mueven los actores, tanto si lo hacen en el escenario propiamente dicho como entre el público". (Pavis, 1983. Pág. 156)

Es imprescindible establecer un paralelismo entre el espacio como concepto del arte escénico y el protagonismo que éste ha tomado en la vida cotidiana. Felisa de Blas en El teatro como espacio nos guía por la historia de la interpretación y las distintas fases por las que transita en espacio como elemento de la puesta en escena; si bien es cierto que en el paso del teatro del siglo XIX al XX, el espacio en el teatro se vuelve relevante, se convierte

\footnotetext{
${ }^{22}$ López, M. Arte, feminismo y posmodernidad: apuntes de lo que viene. En Arte, Individuo y Sociedad, 4, 103-109, Ed. Complutense, Madrid 1991-91.
} 
en un sistema de signos propios con un significado concreto, un lenguaje con los demás condicionantes del montaje teatral.

El espacio para el espectáculo no es una 'idea a priori', como diría Inmanuel Kant, ni tampoco es únicamente una necesidad funcional; es un agente que participa en la comunicación y en la vivencia creando sus propias redes de significado.

La organización espacial contribuye a la instauración de algunos tipos de relaciones psicofisiológicas entre la acción dramática y el espectador, de modo que dos espectáculos desarrollados en espacios con diferente estructura son aprehendidos de forma incluso opuesta por el espectador.

El espacio significante en el espectáculo surge desde el primer momento, aunque no se realice manipulación o construcción previa alguna. Con el simple gesto o movimiento del actor el espacio se dilata, se contrae o arremolina produciendo de forma natural el círculo de espectadores, cerrado, íntimo, distante, participativo o contemplativo. Sólo con el atuendo o con la única inclusión de un objeto, se producen nuevos y variados significados que traen consigo múltiples connotaciones. (de Blas, 2009. Pág.251)

Las concepciones del espacio y del tiempo son parámetros dados de por sí, coordenadas que nos sitúan, que dan cuenta de actos. Este hecho es de sobra conocido por el arte escénico, por ello, en el espectáculo se usan las herramientas necesarias con las que comunicar al espectador no sólo con la palabra, sino también con el espacio, generando sus propias significaciones desde el primer momento que el espectador pisa el edificio teatral.

Veamos a continuación cómo entiende Park la ciudad, con la idea de laboratorio que a una escala más pequeña es una comunidad. El ciudadano se construye a sí mismo a través de los espacios que ocupa y las interacciones que en ellos se producen.

La ciudad ha sido descrita como el hábitat natural del hombre civilizado. En la ciudad, el hombre ha desarrollado la filosofía y la ciencia, y se ha convertido no sólo en un animal racional sino también en un animal sofisticado. La ciudad y el entorno urbano representan para el hombre la tentativa más coherente y, en general, la más satisfactoria para recrear el mundo en que vive de acuerdo a su propio deseo. Pero si la ciudad es el mundo que el hombre ha creado, también constituye el mundo donde está condenado a vivir en lo sucesivo. Así pues, indirectamente y sin tener plena conciencia de la naturaleza de su obra, al crear la ciudad, el hombre se recrea a sí mismo. En ese sentido y en este aspecto podemos concebir la ciudad como un laboratorio social. (Park, 1999. Pág. 57)

Las mujeres presentes en este artículo son parte de las identidades de esa comunidad. Ocupan el caso de estudio los espacios destinados son los lugares destinados a la cultura como en el caso del Teatro María Guerrero o a esas plazas públicas como en el caso de Clara Campoamor. Hay una presencia de todas ellas en el espacio público, ya sea este entendido como calle o aquellos otros espacios que son públicos también pero que entran dentro del ámbito institucional como es el caso de las obras que se encuentran en colecciones de Museos de Titularidad Estatal como el retrato de Isabel II o Catalina de Aragón en el Museo Nacional del Prado y el Museo Thyssen-Bornemisza, respectivamente. Otro de los espacios públicos son las Universidades como el caso de María Isidra de Guzmán y de la Cerda. 
Citando a Celia Amorós y su concepto de genealogía "[...] dicho de otro modo, se la genealogía ya no vehicular el sentido, como desheredados del sentido tendremos que reinventarlo" (Amorós, 2014. Pág.112) y éste es uno de los sentidos de la presente investigación, el hecho de poder crear una suerte de genealogía femenina, una tradición en la que apoyarnos. Se trata de poner de manifiesto el por qué han sido, son y serán importantes estas mujeres para la historia de la ciudad de Madrid.

La intención de este estudio no es más que la de ayudar a entender la construcción de las identidades femeninas en la Historia de la ciudad de Madrid desde las representaciones artísticas con una perspectiva de género. Podemos concluir que hay una presencia física de las biografías de las mujeres que hemos analizado en este artículo en el entorno urbano de la ciudad de Madrid. Esta presencia supone un modo de construir identidad colectiva.

\section{Bibliografía}

Amorós, Celia (2014) Salomón no era sabio. Madrid: Fundamentos.

APARICI, R. (2010) La construcción de la realidad en los medios de comunicación. Madrid: UNED.

Benhabid, Seyla Feminismo y Posmodernidad: Una difícil alianza en de Miguel, Ana y Amorós, Celia (cord.) (2005) Teoría feminista: de la ilustración a la globalización Madrid: Minerva

BERGER, J. (2010) Modos de ver. Barcelona: Gustavo Gili.

BuRDIEL, I. (2011) Isabel II: una biografía (1830-1904) Barcelona: Taurus

De ArteagA, A. (2018) Catalina de Aragón: reina de Inglaterra. La Esfera de los Libros.

De Blas, FelisA, FelisA. (2009) El teatro como espacio. Barcelona: Fundación Caja de arquitectos.

DE DiEgo, E. (1987) La mujer y la pintura del XIX español. Madrid: Arte Cátedra.

De la Plata, V. M. M. (2005) Mujeres renacentistas en la corte de Isabel la Católica:[Beatriz de Bobadilla, Beatriz Galindo, Lucía de Medrano, Beatriz de Silva, Catalina de Aragón, María Pacheco] (Vol. 14). Editorial Castalia.

DíAz, T. D. (2008) Santa María de la Cabeza, única santa nacida en la provincia de Guadalajara (Caraquiz, Uceda), de origen judeoconverso. In El culto a los santos: cofradías, devoción, fiestas y arte (pp. 637-654). Ediciones Escurialenses.

EAREnfight, T. M. (2016) Raising Infanta Catalina de Aragón to be Catherine, Queen of England de Catalina de Aragón a Catalina de Inglaterra: la educación de una infanta. Anuario de Estudios Medievales, 46(1), 417-443.

FERNÁNDEZ Quintanilla, P. (1979) Una española ilustrada: Doña María Isidra Quintina de Guzmán y de la Cerda. Universidad de Salamanca, Revista Tiempo de Historia, no 60, Ferrandez, V. M. P. Y. (2012) María Isidra de Guzmán y de la Cerda 1768-1803: la primera mujer doctora en Filosofía y Humanidades. Hidalgos: la revista de la Real Asociación de Hidalgos de España, (529), 57-60. 
Gorgas Berges, A.I. (2019) Pactos entre mujeres: Ecos soportales en la narrativa de María de Zayas y Sotomayor. Madrid: Universidad Carlos III de Madrid.

JAIme DE PABLOS, Ma ElenA (2009) Identidades femeninas en un mundo plural Sevilla: Arcibel editores

LiPOVETSKY, GILLES (2002) Tercera Mujer: permanencia y revolución de lo femenino Barcelona: Editorial Anagrama.

López, M. Arte, feminismo y posmodernidad: apuntes de lo que viene. En Arte, Individuo y Sociedad, 4, 103-109, Ed. Complutense, Madrid 1991-91

LuKÁcs, Georg (1974) Estética. Obras Completas, v. I.-IV. Barcelona: Ediciones Grigalbo, S.A. MAYAYO, P. (2003) Historias de mujeres, historias del arte. Madrid: Cátedra.

Molledo, J. M. S. (2009) Iconografía de San Isidro Labrador y Santa María de la Cabeza. Pasos de arte y cultura, (9), 66-68.

PARK, R. E. (1999) La ciudad y otros ensayos de ecología urbana. Barcelona: Ediciones del Serbal.

Palmer, M. D. C. S. (2008) Manuela Malasaña Oñoro, la heroína accidental. Ilustración de Madrid: revista trimestral de la cultura matritense, (7), 53-56.

Pavis, P. (1983) Diccionario del teatro. Dramaturgia, estética y semiología. Barcelona: Paidós.

Pink, S. (2020) Women and Bullfighting. Gender, Sex and the Consumption of Tradition. Nueva York: Routledge

Rudat, E. M. K. (1975) Ilusión y desengaño: el feminismo barroco de María de Zayas y Sotomayor. Letras femeninas, 1(1), 27-43.

VAlCÁRCEL, A. (2008) Feminismo en el mundo global: época de cambios o cambio de época Madrid: Cátedra

Viedma García, M. (2019) Clara Campoamor, la mujer inapropiable en Sur: Revista de literatura $\mathrm{n}$ - 13.

VV.AA. (2009) Heroínas y patriotas. Mujeres de 1808. Madrid: Cátedra.

Wolf, Mauro (1982) Sociologías de la vida cotidiana. Madrid: Ediciones Cátedra. 